\title{
Chapter 1 \\ Introduction and Summary to Poverty \\ Reduction Policies and Practices \\ in Developing Asia
}

\author{
Almas Heshmati, Esfandiar Maasoumi and Guanghua Wan
}

\begin{abstract}
A sustained rapid economic growth to reduce multidimensional poverty is a policy challenge facing developing Asia and the globe. This book is a joint effort to analyze poverty reduction in Asia. The focus is on drivers, best practices, and policy initiatives. This introductory chapter presents the background to the project and summarizes the contributions to this volume. It includes theoretical, methodological, and empirical research and policy-oriented papers with the aim to advance the measurement of poverty and poverty reduction policy analysis. The studies focus on: poverty alleviation with microfinance, urban, and rural poverty reduction policies, climate change and well-being, dimensions of poverty and its reduction, and decomposing poverty into its component sources. This edited volume by employing diverse up-todate data and methods provide a wealth of empirical evidence and sound recommendations to policymakers and researchers in developing Asia to design and implement effective and inclusive policies and strategies to reduce poverty.
\end{abstract}

\subsection{Background and Motivation}

The major policy challenges facing developing Asia are how to sustain the rapid economic growth that reduces multidimensional poverty and is both socially inclusive and environmentally sustainable. Population growth, rapid urbanization,

\footnotetext{
A. Heshmati $(\bowtie)$

Sogang University, Seoul, Republic of Korea

e-mail: heshmati@sogang.ac.kr

E. Maasoumi

Emory University, Atlanta, USA

e-mail: esfandiar.maasoumi@emory.edu

G. Wan

Asian Development Bank, Manila, Philippines

e-mail: gwan@adb.org
} 
provision of services, the need to reverse declined economic growth after the 2008 global financial crisis, and responding to climate change are among other challenges facing Asia. Asian Development Bank, in collaboration with Sogang University and Emory University, organized a workshop on "Poverty Reduction in Asia: Drivers, Best Practices, and Policy Initiatives" which was held at Sogang University, Seoul, Republic of Korea, August 23-24, 2013. Several prominent economists specializing in poverty analysis were invited to attend the workshop.

This edited volume is based on a selection of papers submitted to the workshop on poverty reduction and related issues in developing Asia-Pacific. Theoretical, methodological, and empirical research and policy-oriented papers were sought, with findings, conclusions and policy recommendations based on solid evidence and appropriate methods. The goal was to advance the development of new tools and measurement of multidimensional poverty and poverty reduction policy analysis. The papers could focus on Asia as a whole, a group of countries, or individual economies.

A total of 135 papers were received in response to the call for papers. From these, a number of papers were selected and anonymously reviewed for this edited volume. Following a two-stage review process and revisions based on comments and suggestions made by the referees and editors, 14 chapters were shortlisted for publication. These are organized into a number of individual and groups of developing Asia country studies focusing on: poverty alleviation with microfinance; urban and rural poverty reduction policies; climate change and well-being; dimensions of poverty and its reduction; and methodological issues decomposing poverty into its component sources. A brief summary of individual chapters is provided below.

\subsection{The Book}

\subsubsection{Part One: Poverty Alleviation with Microfinance}

This section contains two chapters. The first study (Chap. 2) "Poverty Alleviation with Microfinance: Bangladesh Evidence" is by Moshin Habib and Christine Jubb. As the title suggests, the study provides evidence of the impact of membership of a microfinance institution in Bangladesh on poverty alleviation. Using a quasi-experimental approach with a control group, interviews with members of a prominent Bangladesh microfinance institution were conducted in relation to their material possessions. Results show that in almost every aspect of material well-being, including income, ownership of assets, savings, and food intake, members of the microfinance institution are significantly better off than non-members when examined on a univariate basis. In multivariate tests, microfinance institution membership is found to be associated with higher household income and, further, household wealth, measured in terms of savings and is associated with longer membership of a microfinance institution.

The second study (Chap. 3) entitled "Does Microcredit Help the Poor and Financially Marginalized Communities? National Experience of Pakistan Poverty 
Alleviation Fund (PPAF)" is by Zahoor Khan and Jamalludin Sulaiman. This study evaluates the microcredit program of PPAF. Micro-survey data collected during the loan periods comprising January 2003 to December 2006 and January 2004 to December 2007 were used, with a sample size of 2,070 respondents. The impact of the microcredit program on their clients was evaluated by using descriptive statistics, multiple regression, the mean difference model, and quartiles. The study reveals that PPAF does not focus on the extreme poor and marginalized segments in its operational areas because less than $25 \%$ of the total credit was allocated for three extreme classes of the poor, while the remaining $75 \%$ credit was disbursed among the vulnerable poor. Despite an overall positive impact, the program did not benefit the lower quartile community members during the study period.

\subsubsection{Part Two: Climate Change and Well-Being}

This part contains one study (Chap. 4) "Climate Change, Agricultural Production, and Poverty in India” by Saibal Kar and Nimai Das. The low-income group households in the South Asian countries are highly sensitive to climate-intensive sectors like agriculture and its related food production system. Therefore, climate-induced supply shortfalls in agriculture and, consequently, rising food prices can significantly impact the socioeconomic well-being of these households. The tension between economic development, climate change and agricultural production offers a challenging research question not dealt with in recent studies for India. This study explores the effect of climate change on farmland value and subsequently of a counterfactual measure of the farm revenue on rural consumption expenditure under alternative climate change scenarios. The results show a discerning impact of climate change on net revenue and, hence, the well-being of rural people.

\subsubsection{Part Three: Urban Poverty Reduction Policies}

This part consists of two chapters. The first study (Chap. 5) which is on "Urban Poverty in Developing Asia: Dichotomy between the Income and Non-Income Dimensions: Are We Not Grossly Underestimating its Incidence?" is by Dibyendu Samanta. It looks at the acute non-income deprivations visible in urban developing Asia, underlining that a focus on income poverty alone overlooks many critical dimensions of urban poverty. There are evidences to prove that there is a stark dichotomy between the income and non-income indicators of urban poverty and a gross underestimation of urban poverty in developing Asia. There is, thus, a need to broaden the definition of urban poverty in developing Asia, beyond the threshold of meeting the survival needs of food to an approach that looks at a minimal set of basic needs and capabilities for the urban population. This approach takes 
into account the huge deprivations related to shelter, access to basic infrastructure, access to health, education and social welfare, vulnerability in working conditions, and working poverty. This study shows that adopting broadened and higher poverty thresholds is critical for focusing policy attention on the right target group.

The second study (Chap. 6) "Housing Poverty and Inequality in Urban India" is by Sohail Ahmad. Inequitable distribution of resources, including physical capital such as housing, has posed a threat to sustainable development. Through a case study of housing in urban India that focuses on renter and slum dwellers, this study documents housing inequality and poverty, examines whether and why there is a gap in living standards, and estimates housing demand. Using household survey data, the study provides a decomposition analysis of the causes of inequality and estimates housing demands for owner, renter, and slum dwellers. The study results revealed that the average floor area consumption in renter/slum households is about two-thirds of the owner households. The inequality is attributed to differences in endowment levels and "rates of return" to these endowments. Ahmad concludes that to enhance housing consumption among renter/slum dwellers, there needs to be a focus on upgrading high-skill occupations and stable employment status, rather than just income improvement strategies.

\subsubsection{Part Four: Rural Poverty Reduction Policies}

This part comprises two chapters. The first study (Chap. 7) entitled "Evaluation of the Policy of Crop Diversification as a Strategy for Reduction of Rural Poverty in India" is by Aparajita Mukherjee. This paper examines the effectiveness of crop diversification in ensuring greater availability of food and nutrition to the rural poor in India. It undertakes empirical investigation with primary farm-level data to examine the extent and severity of poverty and food deprivation among the very marginal, marginal, and small farmers practicing crop diversification in different degrees, in three districts of an Indian state. The test results indicate an inverse association between the extent of crop diversification and the calorie intake per capita across the districts. In areas suffering from adverse soil and other characteristics, the small and marginal farmers are compelled to diversify away from waterintensive traditional crops to ensure a minimum acceptable level of consumption. However, they find it hard to avoid poverty and malnutrition. In contrast, in places without publicly supplied cheap irrigation facilities where the farmers develop access to irrigation through private investment, crop diversification enables the small and marginal farmers to maintain some reasonable level of consumption and positive net income. However, high-value crop production results in low profitability and relative inefficiency. The study indicates that a more direct policy intervention is needed to ensure effectiveness of crop diversification as a strategy for reduction of rural poverty in India.

The second study (Chap. 8) "Conflict and Livelihood Decisions in the Chittagong Hill Tracts of Bangladesh" is by Muhammad Badiuzzaman and Syed 
M. Murshed. They analyze rural household livelihood and child school enrolment decisions in the post-conflict setting of the Chittagong Hill Tracts region of Bangladesh. The study uses current subjective perceptions regarding the possibility of violence in the future and past actual experiences of violence to explain household economic decision-making. Preferences are endogenous in line with behavioral economics. Regression results show that heightened subjective perceptions of future violence and past actual experiences of conflict influence current consumption and child enrolment and are likely to encourage risky mixed crop cultivation. The trauma emanating from past experiences combined with current high perceptions of risk of violence may induce bolder and riskier behavior in line with prospect theories of risk. Moreover, a post-conflict household-level Phoenix or economic revival factor may be in operation, based partially on greater intragroup trust.

\subsubsection{Part Five: Dimensions of Poverty and Its Reductions}

This part contains three studies. The first study (Chap. 9) "Decomposing Spatial Inequality in Sri Lanka: A Quantile Regression Approach" is by Thusitha Kumara. This paper uses the Blinder and Oaxaca decomposition method and its recent expansion by Machado and Mata to examine if well-being gaps between urban (richer regions) and rural (poorer regions) areas are the result of (i) regional/spatial differences in household characteristics or (ii) differences in location-specific returns to these characteristics. The data used in this study are from the household income and expenditure surveys for 2006/07 and 2009/10. The analysis suggests that the existence of barriers, such as remoteness and poor access to markets, that prevent lagging regions from being absorbed into the modern sector or growing region plays a larger role in perpetuating spatial inequality, especially for the poor, as compared to disparities in household characteristics (endowments) between regions and sectors.

The second study (Chap. 10) entitled "Non-Income Dimensions, Prevalence, Depth and Severity of Poverty-Spatial Estimation with Household-level Data in India" is by Panchanan Das. This paper examines the incidence, depth, and severity of poverty and the effects of the major non-income dimensions on poverty in India by using the 61st and 66th rounds of NSS household survey data. Poverty estimates are based on relative poverty lines at $75 \%$ and $50 \%$ of the median value of the distribution of per capita expenditure of the respective population groups. It focuses mainly on education, type of employment, land rights, social and religious factors, and gender-related issues in the non-income dimensions of poverty. The rising poverty incidence on the basis of the relative poverty line in urban areas supports the hypothesis that urban inequality has increased significantly during the post-reforms period in India. Per capita consumption expenditure on a monthly basis is used as a proxy for well-being or poverty. The study observes that land as a productive asset had very little positive effect on poverty. But the 
effect of education on the level of well-being was positive and increased with the level of education in every state. Technical education, a component of workers' skills, improved consumption per capita in all states excepting for Chhattisgarh and Kerala. Scheduled Tribes and Scheduled Castes among the social groups and Muslims among the religious groups are mostly deprived in terms of consumption per capita.

The last study (Chap. 11) entitled "Is Poverty Comparable across Varying Size of Population among Indian States?" is by Balakrushna Padhi and Mohammad $\mathrm{K}$. Khan. The most popular measure of poverty, that is, the head count ratio is undoubtedly a simple measure with inadequacies of comparison. It also suffers from the mismatched contradiction between the count of the poor and their share in the population. Such inadequacies point toward its limitation in comparing poverty head count ratio across varying population sizes. Given these concerns, the measure of poverty accounting for its absolute count, intensity, as well as inequality is proposed here as a modified version of the Sen, Shorrock, and Thorn measure of poverty. Further, a decomposition exercise is carried out to comprehend the share of each of its components in the changing level of poverty, which is illustrated using the Indian data set. The salient observation made here relates to declining poverty levels in Indian states being in disagreement with reduced illfare as the poverty gap is on a rise along with the count of the poor. This raises apprehensions as to whether poverty reduction has to less to do with the changing state of the poor than the changing state of the non-poor.

\subsubsection{Part Six: Sustainability in Poverty Reduction}

This part contains two studies. The first study (Chap. 12) "The Role of Foreign Labor Migration and Land in Poverty Reduction: A Case of Nepal" is by Ramesh Sunam. Nepal has witnessed a decline in poverty in the last decade, although GDP growth is low and stagnant at around $4 \%$. The causes behind this decline are little known. Why certain households have a tendency to fall into poverty is also an area of poverty dynamics that has not been studied. This paper seeks to examine to the causes behind poverty dynamics in rural Nepal. It shows that nearly $29.5 \%$ of the total 386 households studied have escaped poverty, while $7 \%$ have fallen into poverty over two recent decades. Foreign labor migration, small business, and access to land define the movement of most households out of poverty, whereas loss of land, cultural burdens, and health costs are the main factors associated with descent into poverty. This paper suggests that two distinct sets of policies are required for addressing poverty-one set to enable escape from poverty and another set to prevent decline into poverty. Such policies need to consider the situation of the poor who cannot pursue labor migration and the left-behind household members, enabling their access to land for farming and creating local employment.

The second study (Chap. 13) entitled "Does Poverty Alone Keep Children Out of School? The Case of Children under Kinship Care in the Philippines" is 
by Joseph J. Capuno and Xylee Javier. While the importance of child education is universally recognized, there are millions of children who are out of school in developing countries. Many of these children are left in the care of their kin when their parents die or go to work abroad. This paper examines the welfare, particularly in terms of school attendance, of the children under kinship care in the Philippines. The household survey data set comprises 1,485 households with at least two members in the 6-12 years age group and one of these being the household head's child or grandchild and the other being the head's kin. Applying probit regression models, they find that a child under kinship care is about $3 \%$ points less likely to be attending school than the head's child, other things being constant. However, there are no such statistically significant differences between the head's child and grandchild. While deprivation keeps some children out of school, ensuring their schooling participation would require more transfers than are needed to lift their households out of poverty. Targeting these children through conditional cash transfer programs could mitigate the effect of the apparent parental bias.

\subsubsection{Part Seven: Alleviation of Poverty in Asia and the Pacific}

This last part contains two studies. The first study (Chap. 14) entitled "Economic Class and Labor Market Segregation: Poor and Middle-class workers in Developing Asia and the Pacific" is by Phu Huynh and Steven Kapsos. Using an absolute definition of poverty and economic classes, this paper presents trends and estimates of the poor, near poor, and middle-class working population in developing Asia and the Pacific. It reveals that since 1991, working poverty has fallen remarkably, while middle-class jobs now account for nearly two-fifths of all employment in the region (671 million middle-class workers). However, a sizeable share of workers (around $28 \%$ or 497 million) still lives just above the poverty line and remains highly vulnerable to falling into poverty. The paper also applies a class-based framework for assessing inequality in the labor market, with a special focus on Cambodia, India, Indonesia, and Viet Nam. It provides empirical evidence that economic participation is inversely related to affluence, while educational attainment and access to better quality jobs both increase with higher economic class status. In addition, it presents sex-and age-disaggregated analysis to highlight particular gaps for poor women and youth and suggests the measures that can help strengthen their position in the labor market.

The second and last study (Chap. 15) entitled "Foreign Direct Investment and the Poverty Reduction Nexus in Southeast Asia" by Nathapornpan P. Uttama attempts to empirically investigate the determinants of FDI and related factors on ASEAN's poverty reduction and focuses on spatial quantitative empirical evidence available on the ASEAN region. The spatial specification model is constructed and estimated by using the spatial panel data model technique. It is empirically estimated on the basis of a crucial assumption that individual country-specific factors such as globalization, 
finance, politics, infrastructure, and spatial FDI have an impact on poverty reduction in ASEAN. Data at the country level for ASEAN-6 during the period 1995-2011 are used. The analyses confirm the positive significant relationship between FDI inflows and poverty reduction in ASEAN, in terms of both individual and spatial aspects. Nevertheless, this relationship is significantly different between other factors and poverty reduction in ASEAN. For instance, while the relationship remains positive and significant for GDP growth, openness and foreign debt, it is significant negative for financial and infrastructure factors and ambiguous for political factors. The results are also robust to alternative model specifications. It concludes that FDI is conducive to poverty reduction.

This edited volume is authored by technical experts in the field who employ diverse up-to-date data and methods to provide empirical results based on representative household surveys, covering several countries in Asia and the Pacific. It contains a wealth of empirical evidence and sound recommendations to policymakers and researchers to design and implement effective policies and strategies to prevent and reduce poverty. The book is a useful resource to policymakers and researchers at national and international research institutes, universities, nongovernmental, and governmental organizations involved in fighting poverty. It can also be used as a supplementary textbook in teaching advanced undergraduate or postgraduate courses in poverty, inequality, and welfare economics. Finally, the book appeals to a broader audience interested in economic development, resources, policies, and economic welfare and growth.

Open Access This chapter is distributed under the terms of the Creative Commons Attribution Noncommercial License, which permits any noncommercial use, distribution, and reproduction in any medium, provided the original author(s) and source are credited. 